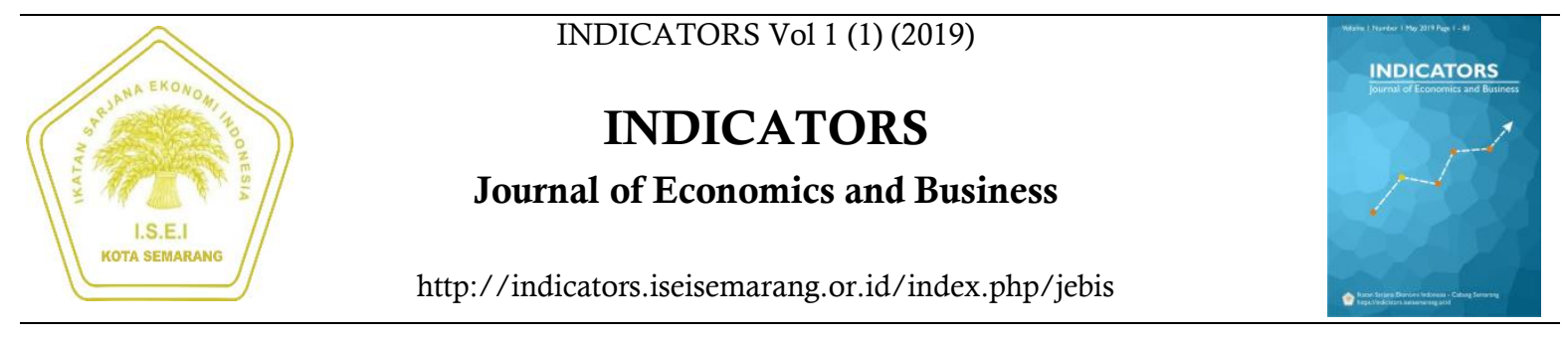

\title{
Strategi Pengembangan Objek Wisata International Sport Club di Kota Semarang
}

\section{Resta Giri Putranto ${ }^{1 凶}$, Fafurida ${ }^{2}$}

Jurusan ekonomi pembangunan, Fakultas Ekonomi, Universitas Negeri Semarang

\section{Info Artikel Abstrak}

Sejarah Artikel:

Diterima Februari 2019

Disetujui Mei 2019

Dipublikasikan Mei 2019

\section{Keywords:}

Development Strategy,

Tourist Attraction
International Sport Club (ISC) merupakan objek wisata yang kurang berkembang di kota Semarang karena mengalami penurunan jumlah kunjungan wisatawan tiga tahun berturut-turut. Tujuan penelitian ini adalah untuk mengetahui dan mengidentifikasi kondisi lingkungan internal dan eksternal objek wisata ISC dan menyusun strategi yang dapat dikembangkan oleh pihak pengelola untuk memikat pengunjung dan menambah pendapatan objek wisata ISC. Penelitian ini bersifat kuantitatif. Penelitian ini menggunakan analisis SWOT. Populasi dalam penelitian ini adalah pengunjung objek wisata ISC. Hasil analisis SWOT menyimpulkan bahwa ISC berada pada kuadran II, dimana situasi tersebut yaitu dapat memanfaatkan kekuatan untuk memanfaatkan peluang jangka panjang melalui cara diversifikasi. Saran dari penelitian ini adalah perlu adanya pengkajian harga kembali tiket masuk, memanfaatkan promosi melalui media online atau media sosial, diversivikasi fasilitas olahraga dan kerja sama dengan investor untuk pengembangan objek wisata ISC.

\section{Abstract}

International Sport Club (ISC) is a less-developed tourist attraction in Semarang city, due to decline of the number of tourists visit three years in a row. The purpose of this research is to find out and to identify the internal and external conditions, and devise the strategies that can be developed by officials to lure visitors and increase the income of ISC. This research is a quantitative research. This research use SWOT analysis. The population in this research is the visitors. The results of SWOT analysis concluded that ISC is in quadrant II, where the situation is able to harness the strength to leverage long-term opportunities through diversification strategy. The advice of this research is the study of the price of the return ticket, take advantage of the promotion through social media or online media, do diversification sports facilities and working with investors for the development of tourism in ISC.

\footnotetext{
${ }^{\square}$ Alamat korespondensi:

J1. Erlangga Tengah No.17, Semarang, 50229

E-mail: restagp@gmail.com
} 


\section{PENDAHULUAN}

menjadi kebijakan prioritas yang dapat ditempuh dimasa yang akan datang guna menggerakkan perekonomian nasional dan meningkatkan pertumbuhan ekonomi. Pengembangan kepariwisataan dinilai penting karena pariwisata memiliki keterkaitan dengan sektor-sektor lain seperti sektor pertanian, jasa, perdagangan, dan sektor transportasi. Pengembangan dan pendayagunaan pariwisata secara optimal akan mampu meningkatkan pertumbuhan ekonomi, menciptakan lapangan kerja, meningkatkan pendapatan masyarakat dan pendapatan daerah (Yoeti, 2008). Kota Semarang memiliki berbagai objek wisata dan event yang dapat dijadikan tempat untuk para wisatawan melakukan liburan, serta para pemangku kepentingan kegiatan pariwisata untuk mendapatkan keuntungan dari kegiatan tersebut.

Tabel 1. Persentase Pengunjung dan Pendapatan Objek-Objek Wisata Di Kota Semarang

\begin{tabular}{|r|l|r|r|r|r|}
\hline \multirow{2}{*}{ No } & \multirow{2}{*}{ Nama Objek Wis ata } & \multicolumn{2}{|c|}{ Persentase } & \multicolumn{2}{c|}{ Persentase } \\
\cline { 2 - 6 } & & $\mathbf{2 0 1 4}$ & $\mathbf{2 0 1 5}$ & $\mathbf{2 0 1 4}$ & $\mathbf{2 0 1 5}$ \\
\hline 1 & Goa Kreo & & $25 \%$ & & $102 \%$ \\
\hline 2 & Hutan Wisata Tinjomoyo & $89 \%$ & $20 \%$ & $204 \%$ & $-34 \%$ \\
\hline 3 & Kampoeng Taman Lele & $2 \%$ & $116 \%$ & $155 \%$ & $-30 \%$ \\
\hline 4 & MEC Tapak Tugurejo & $-8 \%$ & $8 \%$ & & \\
\hline 5 & Pantai Marina & $39 \%$ & $-22 \%$ & $54 \%$ & $-15 \%$ \\
\hline 6 & Gelanggang Pemuda Manunggal & $11 \%$ & $39 \%$ & $5 \%$ & $9 \%$ \\
\hline 7 & International Sport Club & $-21 \%$ & $-68 \%$ & $-18 \%$ & $-89 \%$ \\
\hline 8 & Kolam Renang Tirta Indah & $-12 \%$ & $21 \%$ & $-4 \%$ & $19 \%$ \\
\hline 9 & Oasis Swimming pool & & & & \\
\hline 10 & Paradise Club & $-26 \%$ & & $-55 \%$ & \\
\hline 11 & Taman Margasatwa SMG & $14 \%$ & $29 \%$ & $7 \%$ & $3 \%$ \\
\hline 12 & Maerokoco & $136 \%$ & $92 \%$ & $130 \%$ & $161 \%$ \\
\hline 13 & Taman rekreasi Marina & & & & \\
\hline 14 & Taman Ria wonderia & $-1 \%$ & $-51 \%$ & $-32 \%$ & $-56 \%$ \\
\hline 15 & Water Blaster & $2 \%$ & $-59 \%$ & $7 \%$ & $-20 \%$ \\
\hline 16 & Gereja Blenduk & & & & \\
\hline 17 & Lawang Sewu & $99 \%$ & $42 \%$ & $100 \%$ & $75 \%$ \\
\hline 18 & Makam S. Pdran & & & & \\
\hline 19 & Masjid Agung Jateng & $14 \%$ & $9 \%$ & & \\
\hline 20 & Museum Jamu Nyonya Meneer & $-39 \%$ & $11 \%$ & & \\
\hline 21 & Museum Mandala Bhakti & & & & \\
\hline 22 & Museum Rekor Indonesia & $39 \%$ & $-59 \%$ & & \\
\hline 23 & Museum Ronggowarsito & $285 \%$ & $13 \%$ & & \\
\hline 24 & Sam Poo Kong & $993 \%$ & $6 \%$ & $793 \%$ & $30 \%$ \\
\hline 25 & TBRS & $620 \%$ & $6 \%$ & & $12 \%$ \\
\hline 26 & Vihara Budha Gaya & $3 \%$ & $85 \%$ & & \\
\hline 27 & CFD Pemuda \&Pahlawan & $11 \%$ & $6 \%$ & & \\
\hline 28 & Dugderan & $-38 \%$ & $74 \%$ & & \\
\hline 29 & Semarang Night Carnival & & & & \\
\hline & & & & & \\
\hline
\end{tabular}

Sumber: Dinas Kebudayaan dan Pariwisata Jateng, Diolah

Dari banyaknya objek wisata dan event yang terdapat di Kota Semarang ternyata masih ada objek wisata yang memiliki potensi namun kurang berkembang, salah satunya adalah objek 
wisata ISC (International Sport Club). Penelitian ini mengambil kasus di ISC karena selama periode 2013-2015 ISC selalu mengalami penurunan jumlah pengunjung, bahkan terjadi penurunan drastis pada tahun 2015 dan yang tertinggi diantara objek wisata yang lain yaitu sekitar 68\% jumlah kunjungan pengunjungnya.

Tujuan penelitian ini adalah untuk mengetahui kondisi lingkungan internal dan eksternal objek wisata ISC dan strategi apa yang dapat dikembangkan oleh pihak pengelola untuk memikat wisatawan dan menambah pendapatan objek wisata ISC.

\section{METODE PENELITIAN}

Penelitian ini merupakan jenis penelitian kuantitatif. Penelitian kuantitatif menekankan pada statistik objektif melalui perhitungan ilmiah berasal dari sampel yang telah terpilih untuk menjawab pertanyaan atas survei dan pendekatan penelitian kuantitatif berasal dari data. Populasi dalam penelitian ini adalah pengunjung yang melakukan kegiatan wisata di ISC karena nantinya penelitian ini berdasarkan atas analisis SWOT yang telah dilakukan oleh pengunjung sebagai bahan masukan dan rekomendasi kepada pihak pengelola ISC melalui pengisisan kuesioner SWOT, tentunya dengan sampel yang telah ditetapkan.

Adapun yang dimaksud dengan sampel adalah bagian dari jumlah dan karakteristik yang dimiliki oleh populasi (Sugiyono, 2016). Sampel dalam penelitian ini menggunakan metode insidental random sampling yaitu merupakan teknik penentuan sampel berdasarkan kebetulan/insidental bertemu dengan peneliti dapat digunakan sebagai sampel bila dipandang orang yang ditemui itu cocok sebagai sumber data (Sugiyono, 2016). Untuk mengetahui besaran jumlah sampel ditetapkan pada rata-rata populasi pengunjung ISC tahun 2013-2015 sebagai patokan atau dasar dalam menentukan jumlah sampel, dapat digunakan pendekatan Slovin dan hasilnya adalah 100 responden.

Penelitian ini nantinya menggunakan variabel-variabel yang terdapat pada analisis SWOT yaitu berupa analisis faktor internal dan faktor eksternal objek wisata ISC. Setelah melakukan pengamatan dan wawancara kepada pihak pengelola dan pengunjung di ISC maka ditetapkan beberapa variabel yaitu faktor internal berupa kekuatan dan kelemahan serta faktor eksternal yaitu berupa peluang dan ancaman.

Metode pengumpulan data dalam penelitian ini menggunakan dua cara yaitu pengumpulan data primer dan sekunder. Pengumpulan data primer yaitu melalui observasi, wawancara dan kuesioner sedangkan pengumpulan data sekunder yaitu melalui instansi terkait berupa data yang dapat menunjang penelitian ini. Penelitian ini menggunakan metode analisis deskriptif dan analisis SWOT. Metode analisis deskriptif digunakan untuk menjawab rumusan masalah pertama, yaitu untuk mengetahui dan mengidentifikasi bagaimana kondisi internal dan eksternal objek wisata ISC. Sedangkan metode analisis SWOT untuk menjawab rumusan masalah yang kedua, yaitu untuk bagaimana strategi pengembangan objek wisata ISC.

Metode analisis deskriptif merupakan prosedur pemecahan masalah yang diselidiki dengan menggambarkan/melukiskan keadaan subjek/objek penelitian (seseorang, lembaga, masyarakat dan lain-lain) pada saat sekarang berdasarkan fakta-fakta yang tampak atau sebagaimana adanya. Data yang dikumpulkan berupa kata-kata, gambar, dan bukan angkaangka. Data tersebut mungkin berasal dari naskah wawancara, catatan-lapangan, foto, video tape, dokumen pribadi, catatan atau memo, dan dokumen resmi lainnya (Moloeng, 2004).

Analisis SWOT adalah identifikasi berbagai faktor secara sistematis untuk merumuskan strategi. Analisis ini didasarkan pada logika yang dapat memaksimalkan kekuatan (strength) dan peluang (opportunities), namun secara bersamaan dapat meminimalkan kelemahan (weakness) dan ancaman (threats). Hal ini disebut dengan analisis situasi. Model yang paling populer untuk analisis situasi adalah analisis SWOT (Rangkuti, 2015). Tahapan dalam analisis SWOT yaitu tahapan pengumpulan data berupa evaluasi faktor internal (IFAS) dan evaluasi faktor eksternal (EFAS), tahapan penentuan bobot dan skor 
kemudian yang terkahir adalah tahapan analisis berupa hasil model SWOT dan matrik SWOT.

\section{HASIL DAN PEMBAHASAN}

ISC merupakan tempat wisata yang menawarkan pariwisata olahraga. Beberapa fasilitas olahraga terdapat di tempat ini diantaranya adalah dua kolam renang, empat lapangan tenis dan dua lapangan futsal. Ada fasilitas lain penunjang objek wisata ini yaitu tempat parkir, mushola, toilet, loker dan kamar ganti pakaian.

Tabel 2. Evaluasi Faktor Internal (IFAS)

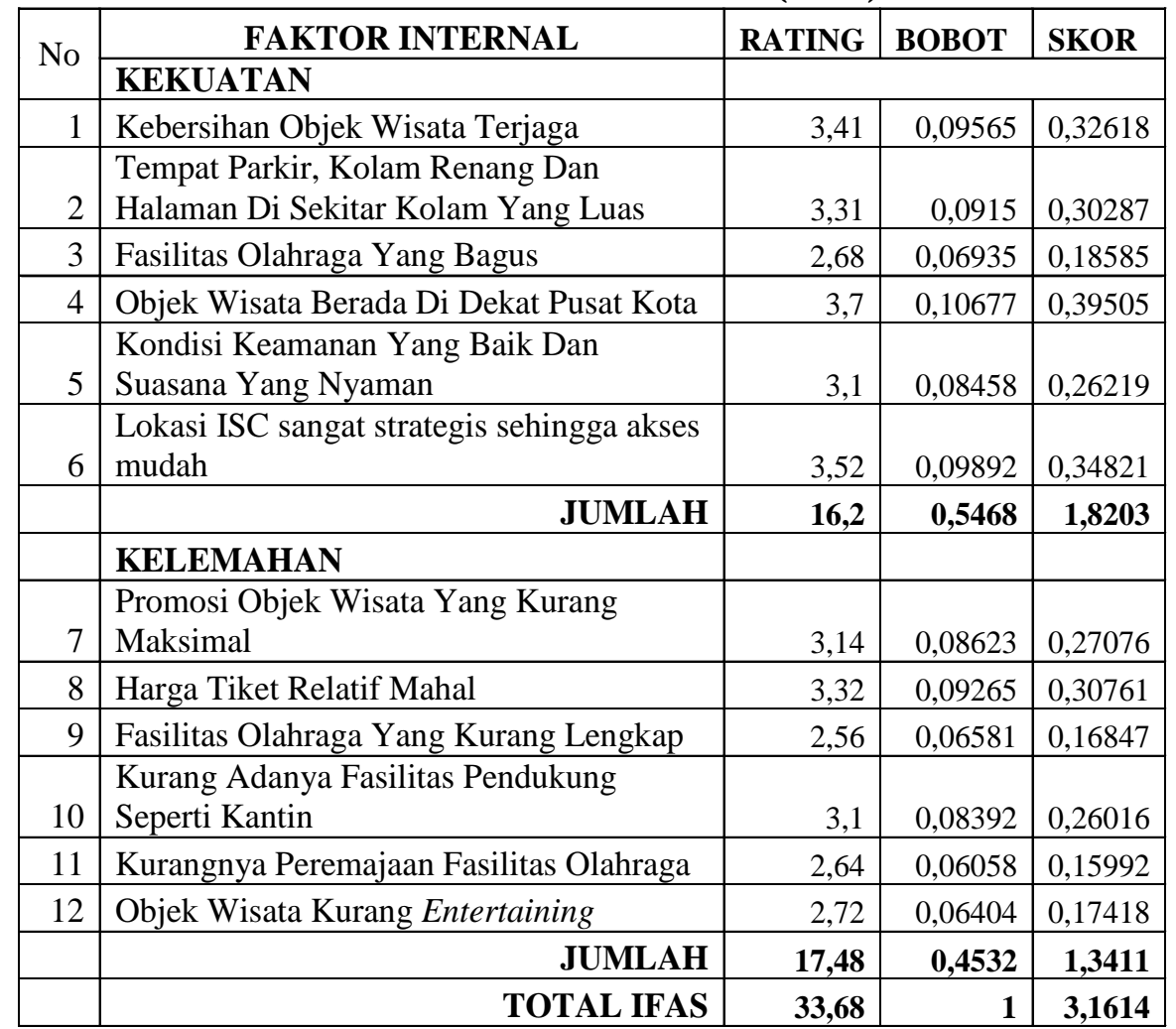

Sumber: Data primer, diolah

Berdasarkan tabel 2 menunjukkan bahwa evaluasi faktor-faktor internal memiliki nilai yang berbeda-beda. Pada faktor kekuatan skor tertinggi berada pada variabel objek wisata berada didekat pusat kota dengan skor 0,39. Hal tersebut menunjukkan bahwa variabel tersebut merupakan variabel terpenting dari faktor kekuatan objek wisata ISC. Adapun kelemahan dalam faktor internal menunjukkan bahwa variabel harga tiket relatif mahal mendapatkan skor tertinggi yaitu sebesar 0,3. Hal ini merupakan hal terpenting dari faktor kelemahan yang harus diperhatikan oleh pihak pengelola
ISC. Dari tabel 3 dapat dilihat bahwa hasil skor faktor eksternal memiliki nilai yang berbedabeda. Pada faktor peluang nilai tertinggi berada pada variabel kemudahan mengakses teknologi sebagai sarana promosi lewat media sosial dengan nilai skor 0,73 . Hal ini berarti variabel tersebut merupakan variabel terpenting dari faktor peluang yang dapat mempengaruhi perkembangan objek wisata ISC. Adapun variabel-variabel dari faktor ancaman seperti variabel belum adanya kesadaran masyarakat untuk berwisata olahraga memiliki nilai skor 0,6 . 
Tabel 3. Evaluasi Faktor Eksternal (EFAS)

\begin{tabular}{|r|l|r|r|r|}
\hline No & \multicolumn{1}{|c|}{ FAKTOR EKSTERNAL } & RATING & BOBOT & SKOR \\
\hline & PELUANG & & & \\
\hline & $\begin{array}{l}\text { Kemudahan Mengakses Teknologi } \\
\text { Sebagai Sarana Promosi Lewat Media } \\
\text { Sosial }\end{array}$ & 3,49 & 0,21067 & 0,73523 \\
\hline \multirow{2}{*}{2} & $\begin{array}{l}\text { Adanya Event Yang diadakan Oleh Pihak } \\
\text { Luar }\end{array}$ & 2,45 & 0,13783 & 0,33769 \\
\hline 3 & Adanya sponsorship dari pihak ke-3 & 2,1 & 0,117 & 0,2457 \\
\hline & \multicolumn{1}{|c|}{ JUMLAH } \\
\hline & $\mathbf{9 6 , 4}$ & $\mathbf{0 , 4 6 5 5}$ & $\mathbf{1 , 3 1 8 6}$ \\
\hline 4 & $\begin{array}{l}\text { ANCAMAN } \\
\text { Dingginya Persaingan Pariwisata Antar }\end{array}$ & 3,05 & 0,17717 & 0,54036 \\
\hline \multirow{2}{*}{5} & $\begin{array}{l}\text { Adanya objek wisata lain yang sejenis } \\
\text { berada di Kota Semarang, }\end{array}$ & 2,88 & 0,1665 & 0,47952 \\
\hline & $\begin{array}{l}\text { Belum Adanya Kesadaran Masyarakat } \\
\text { Untuk Berwisata Olahraga }\end{array}$ & 3,18 & 0,19083 & 0,60685 \\
\hline & \multicolumn{2}{|c|}{ JUMLAH } \\
\hline & $\mathbf{9 , 1 1}$ & $\mathbf{0 , 5 3 4 5}$ & $\mathbf{1 , 6 2 6 7}$ \\
\hline \hline
\end{tabular}

Sumber: Data Primer, Diolah

Nilai skor tersebut memiliki nilai tertinggi dalam faktor ancaman objek wisata ISC. Berdasarkan hasil seluruh uraian mengenai evaluasi IFAS dan EFAS yang telah dilakukan, strategi awal yang dapat dirancang untuk pengembangan objek wisata ISC adalah dengan terus konsisten menjaga dan memaksimalkan kekuatan serta peluang untuk mengatasi kelamahan dan ancaman yang ada. Hasil penghitungan SWOT menunjukkan faktor kekuatan memiliki nilai yang lebih tinggi dari pada kelemahan serta nilai peluang yang lebih kecil dibandingkan dengan ancaman.

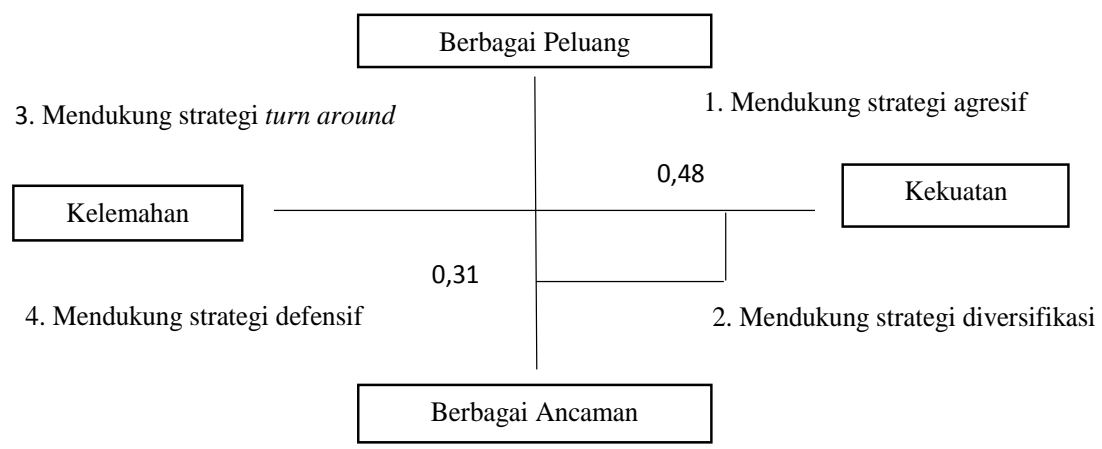

Gambar 1. Matrik Grand Strategy Objek Wisata ISC

Berdasarkan Gambar 1 posisi objek wisata ISC berada pada kuadran 2. Posisi ini menunjukkan bahwa objek wisata ISC memiliki peluang dan ancaman yang dominan dibandingkan dengan kelemahan serta peluang yang ada. Strategi yang diterapkan dalam kondisi ini adalah mendukung strategi diversifikasi.
Analisis matriks SWOT dilakukan setelah seluruh informasi mengenai faktor internal dan faktor eksternal dikumpulkan. Analisis matriks SWOT perlu dilakukan untuk menentukan strategi alternatif seperti apa yang dapat mendukung strategi diversifikasi dan dapat diterapkan untuk pengembangan objek wisata 
ISC sehingga menjadi lebih baik dan jumlah kunjungan wisatawan dapat meningkat. Analisis matriks SWOT dilakukan untuk menghasilkan faktor-faktor lingkungan internal dan eksternal yang terdapat pada objek wisata ISC yang kemudian dapat menjadi strategi alternatif.
Berdasarkan faktor internal dan eksternal kemudian menghasilkan matriks SWOT yang menghasilkan empat bagian kemungkinan strategi alternatif yang mendukung strategi diversifikasi pengembangan objek wisata ISC seperti yang terlihat pada tabel 4.

Tabel 4. Matriks SWOT

\begin{tabular}{|c|c|c|}
\hline & Kekuatan (S) & Kelemahan (W) \\
\hline $\begin{array}{l}\text { Faktor Eksternal } \\
\text { (EFAS) }\end{array}$ & \begin{tabular}{|l} 
1. Kebersihan Objek Wisata \\
Terjaga \\
2. Tempat Parkir, Kolam \\
Renang dan Halaman \\
Disekitar Kolam Renang \\
Yang Luas \\
3. Faslilitas Olahraga Yang \\
Bagus \\
4. Objek Wisata Berada \\
Didekat Pusat Kota \\
5. Kondisi Keamanan Yang \\
Baik Dan Suasana Yang \\
Nyaman \\
6. Lokasi ISC Yang Strategis \\
Sehingga Akses Menuju \\
Objek Wisata Yang Mudah
\end{tabular} & $\begin{array}{l}\text { 1. Promosi Objek Wisata Yang } \\
\text { Kurang Maksimal } \\
\text { 2. Harga Tiket Relatif Mahal } \\
\text { 3. Fasilitas Olahraga Yang } \\
\text { Kurang Lengkap } \\
\text { 4. Kurangnya Fasilitas } \\
\text { Pendukung Seperti Kantin, } \\
\text { Wifi dan Kamar Mandi } \\
\text { Khusus Mandi } \\
\text { 5. Kurangnya Peremajaan } \\
\text { Faslilitas Olahraga } \\
\text { 6. Objek Wisata Kurang } \\
\text { Entertaining }\end{array}$ \\
\hline Peluang (O) & Strategi SO & Strategi WO \\
\hline $\begin{array}{l}\text { 1. Kemudahan Mengakses } \\
\text { Teknologi Sebagai Sarana } \\
\text { Promosi Lewat Media Sosial } \\
\text { 2. Adanya Event Yang } \\
\text { Diadakan Oleh Pihak Luar } \\
\text { 3. Adanya Sponsorship Dari } \\
\text { Pihak Ketiga }\end{array}$ & $\begin{array}{l}\text { 1. Meningkatkan image positif } \\
\text { wisatawan terhadap ISC } \\
\text { sebagai sport club strategis } \\
\text { yang menwarkan beberapa } \\
\text { fasilitas olahraga } \\
\text { 2. Pengembangan dan } \\
\text { peningkatan kualitas produk } \\
\text { atau fasilitas wisata ISC } \\
\text { menjadi lebih menarik } \\
\text { 3. Menjaga dan mengawasi } \\
\text { kebersihan lingkungan ISC }\end{array}$ & $\begin{array}{l}\text { 1. Membuat media sosial } \\
\text { ataupun website sebagai } \\
\text { sarana promosi } \\
\text { 2. Mengikuti berbagai event } \\
\text { dari pihak luar ataupun } \\
\text { mengadakan event sendiri } \\
\text { dan melakukan kerjasama } \\
\text { wisata } \\
\text { 3. Penambahan fasilitas } \\
\text { olahraga dan fasilitas } \\
\text { pendukung serta } \\
\text { peningkatan sarana } \\
\text { prasarana ISC }\end{array}$ \\
\hline Ancaman (T) & Strategi ST & Strategi WT \\
\hline \begin{tabular}{|l} 
1. Tingginya Persaingan \\
Wisata Antar Daerah \\
2. Adanya Wisata Sejenis \\
Yang Berada Di Kota \\
Semarang \\
3. Belum Adanya Kesadaran \\
Masyarakat Untuk \\
Berwisata Olahraga
\end{tabular} & $\begin{array}{l}\text { 1. Inovasi produk atau } \\
\text { melakukan inovasi berbagai } \\
\text { fasilitas ISC agar mampu } \\
\text { bersaing dengan wisata yang } \\
\text { lain } \\
\text { 2. Diversifikasi produk atau } \\
\text { fasilitas agar mampu } \\
\text { bersaing dengan wisatayang } \\
\text { lain } \\
\text { 3. Melakukan promosi akan } \\
\text { pentingnya berwisata } \\
\text { olahraga kepada masyarakat }\end{array}$ & $\begin{array}{l}\text { 1. Menggandeng investor } \\
\text { untuk bekerjasama dalam } \\
\text { hal pengembangan dan } \\
\text { sebagai modal } \\
\text { 2. Pengkajian kembali atas } \\
\text { harga tiket masuk ISC } \\
\text { 3. Penataan pengelolaan objek } \\
\text { wisata sesuai dengan } \\
\text { permasalahan yang dimiliki } \\
\text { oleh ISC }\end{array}$ \\
\hline
\end{tabular}

Hasil analisis menunjukkan bahwa penelitian ini berada pada kuadran II yaitu melalui strategi diversifikasi. Hasil tersebut sama dengan penelitian yang telah dilakukan oleh Lukman Hanif dan Fafurida (2018) tentang strategi pengembangan industri makanan khas di Dieng. Hasil dari penelitian ini berbeda dengan hasil yang dilakukan oleh Tahajuddin (2011) yang meneliti tentang wonderia yaitu dengan hasil strategi agresif atau kuadran I. Hal tersebut dikarenakan hasil penelitian di wonderia memiliki kekuatan dan peluang lebih besar dari pada kelemahan dan ancaman yang dimiliki.

Hasil penelitian ini juga berbeda dengan yang dilakukan oleh Redona (2015) yang meneliti strategi pengembangan gunung Tidar yaitu dengan hasil analisis SWOT berada pada kuadran IV atau strategi defensif, hal ini 
dikarenakan hasil kelamahan dan anacaman lebih besar dari pada kekuatan dan peluang yang dimiliki.

Penelitian yang dilakukan oleh Pradikta (2013) juga memiliki hasil berbeda dengan penelitian ini yaitu dengan hasil analisis SWOT berupa strategi agresif atau kuadaran I, hal ini dikarenakan penelitian ini memiliki kekuatan dan peluang yang lebih besra dari pada kelemahan dan ancaman yang dimiliki. Kemudian penelitian yang dilakukan oleh Furqony (2018) tentang strategi pengembangan Basecamp Mawar di gunung Ungaran juga memiliki hasil yang berbeda dengan penelitian ini yaitu dengan hasil analisis SWOT berada pada kuadran I atau strategi agresif, hal ini dikarenakan faktor-faktor kekuatan dan peluang lebih besar dibandingkan faktor-faktor kelemahan dan ancaman yang dimiliki.

Beberapa perbedaan hasil penelitian ini dengan penelitian terdahulu dapat disebabkan karena faktor-faktor yang ada dalam anlisis SWOT yaitu kekuatan, kelemahan, peluang dan ancaman dari masing-masing objek penelitian memiliki variabel yang berbeda sehingga hasil juga akan berbeda. Hal ini tergantung dengan hasil rating yang diperoleh dari kuesioner SWOT yang telah disebarkan dan diisi oleh pengunjung masing-masing objek penelitian. Dari hasil rating ini kemudian juga akan mempengaruhi perhitungan bobot dan skor dalam analisis SWOT. Kemudian dari hasil skor tersebut didapat perhitungan perbandingan antara kekuatan, kelemahan, peluang dan ancaman lalu hasil dari strategi SWOT diperoleh.

\section{SIMPULAN}

Dari hasil penelitian yang telah dilakukan, maka dapat ditarik kesimpulan sebagai berikut:

Hasil identifikasi kondisi lingkungan internal eksternal objek wisata ISC dapat diketahui bahwa terdapat beberapa faktor yang bisa menjadi kekuatan (strengths), kelemahan (weakness), peluang (opportunities) dan ancaman (threats) dalam pengembangan objek wisata tersebut. Faktor-faktor kekuatan antara lain adalah kebersihan objek wisata ISC terjaga, tempat parkir kolam renang dan halaman disekitar kolam renang yang luas, fasilitas olahraga yang bagus, objek wisata berada didekat pusat kota, kondisi keamanan yang baik dan suasana yang nyaman, serta lokasi strategis sehingga akses menuju objek wisata yang mudah.

Faktor-faktor kelemahan antara lain adalah promosi objek wisata yang kurang maksimal, harga tiket relatif mahal, fasilitas olahraga yang kurang lengkap, kurangnya fasilitas pendukung, dan objek wisata kurang entertaining. Faktor-faktor peluang antara lain kemudahan mengakses teknologi sebagai sarana promosi lewat media sosial, adanya event yang diadakan oleh pihak luar, dan adanya sponsorship dari pihak ke tiga. Faktor-faktor ancaman antara lain adalah tingginya persaingan wisata antar daerah, adanya wisata sejenis yang berada di Kota Semarang, dan belum adanya kesadaran masyarakat untuk berwisata olahraga.

Hasil dari penelitian yang telah dilakukan untuk mengetahui strategi apa yang dapat dikembangkan oleh objek wisata ISC adalah melalui strategi diversifikasi yaitu dengan memanfaatkan fasilitas olahraga yang sudah ada menjadi fasilitas olahraga yang lain, menambah fasilitas olahraga maupun fasilitas pendukung, pengembangan kualitas fasilitas agar menjadi lebih menarik, inovasi produk atau inovasi fasilitas ISC agar mampu bersaing dengan wisata yang lain, optimalisasi promosi dan kerja sama dengan investor untuk pengembangan objek wisata ISC.

\section{DAFTAR PUSTAKA}

Castyana S., Billy, \& Dwikuncoro, Eri P. 2013. Pengaruh Program Pariwisata Olahraga Borobudur Interhash 2012 Dalam Meningkatkan Kunjungan Wisata Kabupaten Magelang. Semarang: Universitas Negeri Semarang.

Disbudapar Provinsi Jateng. 2016. Jumlah Pengunjung Dan Pendapatan Objek Wisata Kota Semarang Tahun 2013-2015. Semarang: Disbudpar Provinsi Jawa Tengah.

Hanif, L., \& Fafurida, F. (2018). Development Strategy of Small Industry of Typical Food as Supporting Tourism Sector. JEJAK: Jurnal 
Ekonomi dan Kebijakan, 11(1), 62-77. doi:https://doi.org/10.15294/jejak.v11i1.12 988

Furqony, M. Izzuddin,. \& Fafurida, F. (2018). Valuation and Development Strategy of Mawar Basecamp in Ungaran Mountain Through Individual Travel Cost Approach. Economics Development Analysis Journal, 6(4),

428-435. https://doi.org/https://doi.org/10.15294/e daj.v6i4.22293

Moeloeng, Lexy. 2004. Metode Penelitian Kualitatif. Bandung: Remaja Rosdakarya.

Pradikta, Angga. 2013. Strategi Pengembangan Objek Wisata Waduk Gunungrowo Indah Dalam Upaya Meningkatkan PAD Kabupaten Pati. Semarang: Universitas Negeri Semarang.
Rajab, Amrullah. 2016. Strategi Pengembangan Objek Wisata Taman Lele Semarang. Semarang: Universitas Diponegoro.

Rangkuti, Freddy. 2015. Analisis SWOT Teknik Membedah Kasus Bisnis. Jakarta: Gramedia Pustaka Utama.

Redona, Rendi. 2015. Strategi Pengembangan Produk Kawasan Gunung Tidar. Yogyakarta: Sekolah Tinggi Pariwisata AMPTA.

Sugiyono, S. 2016. Metode Penelitian Kuantitatif, Kualitatif dan R\&D. Bandung: Alfabeta.

Tahajjudin, Eko Syamsul Ma'arif. 2011. Pengembangan Objek Wisata Wonderia Di Kota Semarang. Semarang: Universitas Diponegoro. 